\title{
Remarkable Reframing
}

\section{Brendan Schütte}

\section{Abstract}

This paper arises from a presentation at the International Mediation and Restorative Practice Conference held at the National University of Ireland, Maynooth on $5^{\text {th }}$ September 2014. The topic is the technique known as reframing.

To reframe is to bring about a change in someone's mental perspective by altering their tacit underlying viewpoint to create different meaning. It is an attempt to release the parties from a blame and counter-blame cycle, and to focus on more useful ways of viewing the conflict. It is not about overlooking or evading some negative sentiment - this needs to be included to maintain the context. What reframing does, however, is to introduce new meaning, co-existent with the negative perspective, which shifts the mind- set towards a more constructive future.

A 'frame' is a cognitive shortcut that people use to make sense of the world. It is a complex mental structure of unquestioned beliefs, values and ideas that is used to simplify our understanding of the world around us and thus to infer meaning.

If a part of that frame is changed - for example through self-reflection, education or reframing then the inferred meaning may also change.

When parties are in conflict their frames help them to interpret what has happened, what the intentions of the other party are, and their own role in what has taken place. This is usually positively disposed to the self and negatively disposed to the other. This lens, or frame, provides meaning for the conflict. Reframing upsets this frame and introduces a different, and potentially more helpful way to look at the conflict so that the parties will work on resolution rather than being stuck on set, negative, unproductive or toxic ways of viewing matters, or being defensive and closed-minded.

\section{Keywords}

Remarkable reframing, mediation, reframing works

\section{Remarkable Reframing}

Not all mediators use as a starting point the idea that actively managing parties' communications is an essential element of their work. But for those who do value such an approach, reframing can be an effective intervention to help parties find their way out of an impasse. It can also be used to encourage parties to consider alternative perspectives to problems, and invite them to search for solutions other than those to which they are initially wedded. Reframing may also be an effective technique when it is important that one party 'see' the other party's point of view. 
Everyone is familiar with reframing, even though we may not have an understanding of the process being used. For example, humour often relies on a reframe:

Question: "How do you get down off an elephant?"

Answer: "You don't. You get down off a duck."

The question appears as a straightforward idea — the method for dismounting from a very large animal. But the answer adds a twist, by using a different meaning for the word "down" used in the initial question. To understand the humour, the listener has to re-interpret the word 'down' in order to understand the story and appreciate the unexpected ending. Reframing is a skill used successfully by politicians and advertisers to change 'hearts and minds'.

In a television debate with Walter Mondale in the 1984 election campaign, Ronald Reagan was asked whether he would be able to handle the demands of the presidency, given his age (he was already the oldest person to serve as President of the U.S. and Mondale was 17 years younger). His reply? "I will not make age an issue of this campaign. I am not going to exploit, for political purposes, my opponent's youth and inexperience." He redirected attention from his age to Mondale's relative youth and avoided addressing the question he'd been asked.

Mediators can respond similarly when one party makes a provocative or challenging statement or asks a question that may not be helpful or timely. For example, after a period of constructive discussion, one party re-introduces an earlier point but presents it in a very blaming manner: "of course, when she passed my probation review, instead of saying "well done", she said "oh, now I won't be able to fire you, ha-ha!" The mediator may respond by saying: "Isn't it refreshing to work for a manager with a sense of humour! Not every manager would be able to trust an employee so much that they feel comfortable to share a joke at review time."

The world of advertising constantly seeks to present products as bigger, brighter, trendier and less risky. Reframing, or 'spinning', how the product is viewed in the eyes of the public can boost sales. Declaring that a product is 'new and improved' may in fact mean nothing more than a change in the product's label or packaging; or the reduction in amount contained in the bag, box or can. Such a statement while factually correct is used to persuade consumers to purchase the product in the belief it is better, has been upgraded or was otherwise enhanced. 'Vaping' is not seen as 'smoking', right? It is still a nicotine delivery mechanism, but the novel term 'vaping' suggests the product does not have the same harmful effects as cigarette smoking.

Looking at things differently can alter the meaning given to an idea, proposal or question. When Copernicus suggested in his 1543 book (De revolutionibus orbium coelestium - On the Revolutions of the Celestial Spheres) that it was the earth that moved around the sun, rather than the other way around, he fundamentally challenged the conventional scientific frame of the time and proposed a new frame for understanding the solar system. In doing so, Copernicus used scientific methods and findings to challenge a cultural—even religious—notion about earth as the central celestial body. 


\section{Reframing - what it is and how it is used in mediation}

Having considered several examples of reframing, and before discussing the application of this technique to mediation practice, it may be useful to have a common understanding of what is meant by a 'frame'. The following definition offers an explanation:

Frames are cognitive shortcuts that people use to help make sense of complex information. Frames help us to interpret the world around us and represent that world to others. They help us organize complex phenomena into coherent, understandable categories. When we label a phenomenon, we give meaning to some aspects of what is observed, while discounting other aspects because they appear irrelevant or counter-intuitive. Thus, frames provide meaning through selective simplification, by filtering people's perceptions and providing them with a field of vision for a problem. (Kaufman, S. et al, 2003)

Framing is the brain's natural distillation process for producing meaning from the myriad pieces of information we absorb from the events and people around us. This process prevents us from being overwhelmed and cognitively paralysed.

The meaning applied to our experiences through framing is neutral in its impact. It is only when one person's frame encounters another person's frame, or a frame is not well-founded, that difficulties can arise.

If framing creates meaning, then it follows that reframing generates an alternative meaning. This is what the mediator wants - to adjust meaning away from what is negative or useless, to open doors out of impasse, to shake the belief in strongly held positions, or to help parties think about options for resolution when they are well disposed to working together but are having difficulty imagining solutions.

Reframing in essence is 'examining the same situation from multiple vantage points to develop a holistic picture' (Bolman L.G. and Deal T.E. 1997). It is not about minimising the seriousness or impact of what has happened, it is about considering how to generate new meaning about the conflict. The idea of reframing is to maintain 'the conflict in all its richness but to help people look at it in a more openminded and hopeful way.' (Mayer 2000).

In examining how mediators use reframing two approaches are presented here - changing frames of perception of the conflict and influencing parties' scripts in how they tell their 'story'.

\section{(a) Perceiving}

Using this 'viewing' or 'seeing' metaphor can help us to expand on how we look at things in mediation, such as:

I. What we focus on;

II. What part of the picture (history, costs or other impact, type of dispute, parties involved) they look at and what part they choose to ignore;

III. Looking at the 'picture' from a different position; and

IV. What they choose to juxtapose. 
I. Mediators can invite the parties to choose, focus and concentrate on a particular issue, while largely excluding other issues. For example, a mediator might sense that the central issue as being the problems in a relationship between two people, and might encourage the parties to ignore, postpone or underemphasise the parties' monetary, environmental or health issues. The assumption is that, once the relationship issues have been resolved, the parties will be more amendable to resolving the other issues.

II. Having heard the parties' stories in detail the mediator can present to the parties the positive elements, however small, that may help them put the negative element into the context of the overall picture of their conflict. Some examples couldbe:

"It seems that generally your relationship has been good, until this once-off incident happened. In what ways have you been able to co- operate?"

"You've both said complimentary things about how you value each other - how can you use that to find a solution now?"

"The main thing I'm hearing is that you both want the mediation process to work."

Instead of looking at just one part of the picture, often the negative element, the reframing encourages the parties to consider their positive experiences, without dismissing, minimising or ignoring the negative experience.

III. At the bottom centre of a famous painting by Hans Holbein the Younger, dated 1533, "The Ambassadors', is an indistinct skull, painted in anamorphic perspective, which means the viewer must approach the painting from the side in order to see the skull in accurate form. The image cannot be seen properly when viewed from directly in front. Similarly, having parties look at their conflict from different positions can also allow them to literally see things differently. This idea of making connections between the position from which you view things and the richness of what you see is reflected in an exercise used in neuro-linguistic programming called 'Perceptual Positions'. The technique is used to enhance flexibility and resourcefulness in the person being coached. In this technique there are three basic perceptual positions:

$1^{\text {st }}$ position: the self- $2^{\text {nd }}$ position: the other

$3^{\text {rd }}$ position: the detached observer

(Shapiro 1998)

Some mediators use this technique (the 'detached observer') in helping parties understand the perception, attitude and goals of 'the other' by asking each party to sit in different seats - firstly the other party's seat and secondly looking back at their own seat, taking the perspective of another family member, work colleague or neighbour. The goal of this exercise is that each person gains insight into the perspective of another and allows new meaning-a new frame-to be formed.

IV. Another helpful intervention asks the parties to look at certain elements of the story or the conflict side by side. The objective is to encourage a new way of looking at things. For example, an interest by one party in getting the detail of a project right, which may have come across to the other as 'micro- 
managing', may be presented as a way to improve the quality of the other party's efforts which had been based on a 'big picture' approach to the project. Instead of seeing 'micro-managing' and 'big picture' as a choice between two opposites, they are placed side byside.

The mediator may say something like: "Let's look at this for a moment. Your concern (Party A) is that the level of scrutiny of your work is excessive and your concern (Party B) is that the detail is important to ensure mistakes are not made. You both want this project to be successful. It seems to me that perhaps your working styles may not be aligned to deliver that success right now. If your (Party A) overall direction and knowledge of the project can be enhanced by your (Party B) help with day-to-day specifics, then shouldn't you be able to address most of the factors needed to ensure the project will be completed on time and to a high standard?"

This allows the party to re-consider his perception of negative 'micro-managing' into something constructive which can improve his own efforts. The meaning is thereby changed and linked to the positive intentions of each party which may have been ignored when viewed in isolation.

\section{(b) Scripting}

How people understand and frame others' actions and words will influence the script they write in response. In conflict this script is often highly negative about the other person but usually quite affirmative about the self. The meaning written into the story is that I am the 'hero' and you are the 'ogre', therefore I am justified in treating you as I do because that is how a 'hero' should treat an 'ogre'. My poor behaviour towards you is therefore turned into a virtue.

The purpose of a "shift" reframe is to restate the negative viewpoint or sentiment of a party by highlighting an underlying need or concern. This kind of intervention allows for a redefinition of the problem in a way the other party can openly and constructively tackle. Rather than simply being defensive the parties can work on addressing each other's fundamental needs in which they may well find common ground. Here are some examples:

- Party says "It's absolutely ridiculous, he has no interest in what I say and most of the time talks over me, it's so rude and ignorant. He's only interested in saying how he feels and what he wants, he has no interest in my point of view at all and never has. He is fully aware that my thesis was on regression analysis and that I have more knowledge on this than him but he insists he has no time to listen because the project must be completed on time. Well, I'm committed to doing a quality job even if he's not. So I don't see how we're going to get anywhere because that's what he's always like."

- Reframe by mediator (into positive, underlying need): "You would like him to hear what you have to say and take it on board because you have a lot to bring to the project, while also being aware of how you feel, and you want him to show some courtesy when talking to you."

This helps the other party to move towards a problem-solving mind-set - the reframe is a 'normal' thing that any human being might need and so the 'normal' reaction is to work on constructing an answer.

- Party says: "This place has become an awful atmosphere to work in. The team is completely 
chaotic and dysfunctional, it's all down to him and how he manages. We're willing to do a great job and to work better with each other but we're not allowed because of his stupid rules and insistence that we can't have a plan as we need to be flexible at all times."

- Reframe by mediator: "You'd like a decent place to work in, with better planning and control, and you want him to work constructively with the team to achieve that."

This reframe opens the way for the party to be involved with the team in defining how the environment should be. It is inclusive rather than critically exclusive and therefore it is more attractive for the party to become actively involved with this.

- Party says: "The problem is that when I ask her what's wrong she just lies through her teeth at me and treats me like a child."

- Reframe by mediator: "You want her to be honest and direct with you and to have an adult to adult conversation."

The reframe assumes the party has a virtuous approach and will be able to take part in an Adult-to-Adult transaction - this implied compliment hooks the party into considering how this will be done.

Once the parties start to see the conflict as unmet needs to be somehow resolved, their energy and focus starts to become re-directed towards developing solutions. A definitional reframe is a more complex intervention, and typically seeks to re-define the lens though which both parties view matters at hand.

Each side has developed their own story that explains the conflict. This story is developed with their own meaning in mind. Impasse can happen when parties focus on attacking each other's story as being wrong, illogical, senseless, crazy, dishonest or simply stupid. In a definitional reframe the mediator helps the parties knit the two stories into one that both can accept. Having a joint story creates additional meaning that assists them in breaking out of the impasse and finding solutions. Example of a definitional reframe:

- Two people live side by side in a small estate. One is an older, retired gentleman, who goes to bed early. The other is younger, often stays out at the pub, and comes home late.

- The younger neighbour owns a dog that he keeps in a shed in his back garden. The dog barks when his owner isn't there, and this keeps the older neighbour awake at night.

- The older neighbour has made a complaint of noise pollution and demands the dog be put down. The younger neighbour insists on his right to keep his dog and says it is well behaved when he is there.

- They have been squabbling during the mediation, each outlining clearly and logically their own views and blaming the other for causing trouble.

In deciding whether and how to employ a definitional reframe, the mediator considers:

What is the common ground? That they can live peaceably as neighbours without engaging in conflict over the dog.

What are their positive underlying needs? For the older gentleman it is to get a good night's sleep, while for the younger neighbour it is to enjoy the company of his pet. Frame the definition of what they are here to do in a non-toxic, blame-free 
way and orientate it towards the future and in terms of resolution.

Thus, the mediator might reframe as follows for the two parties:

"So the task that both of you are here today to work on is to find a way that you can live comfortably side by side as neighbours, that you (party A) can get a good night's sleep and that you (party B) can continue to enjoy the company of your dog."

If this doesn't make sense to the parties, they will debate it and the mediator can try a better reframe. There may be some further iteration until the parties accept a useful reframe. It is the acceptance of a common frame that allows the parties to start working on a solution.

\section{Why reframing works}

Our brains constantly seek a state of harmony among our various attitudes, behaviours, values and beliefs, expectations, and knowledge. When an incompatibility arises an uncomfortable cognitive dissonance disturbs this harmony and demands that something changes. For example, an incompatibility may arise if I smoke a cigarette (behaviour) yet know that it is bad for my health (belief). In order to return to the state of harmony I must change something. This could be to cease the behaviour by immediately throwing away the cigarette, or to rationalise the situation by maintaining that smoking one cigarette won't do any harm (altering belief). This new meaning allows the brain to return to harmony.

This is what happens in reframing. The new information provided by the mediator (i.e. the new way of looking at things) unsettles the parties' cognitive harmony to which the brain must respond. Something must change. One good reframe during a mediation may make all the difference between parties finding a joint approach to solving their conflict or staying stuck like a 'broken record'.

\section{Reframing is a core change skill}

Reframing is an attempt to change meaning in a subtle, nuanced way. It is to effect a slightly different and hopefully more constructive way to look at things rather than just mirroring back what has been said, which is the technique of summarising. Because reframing, if used appropriately, is a vital intervention skill, new mediators must understand the importance of reframing and be given time to practise and master the skill.

It is not the easiest skill to learn or to use and trainee mediators in particular, while they may understand how valuable it can be, seem to find demonstrating it somewhat difficult. Trainers can reflect on how reframing is taught and consider using interesting visual aids, as well as verbal descriptions, to add a richness to the learning experience.

For example, Magic EyeC is a visual puzzle, popular in the 1980s, in which the viewer looks at a picture composed of seemingly random repetitive images. Following instructions to 'unfocus the eyes and look through the picture', the viewer sees a three dimensional illustration hidden in the random images. Use of Magic Eye $\odot$ during training can demonstrate how 'looking at something differently' can result in seeing something new, hidden and more useful such as the concealed three-dimensional image which suddenly appears. 
Use of 'stock' reframes can help to embed the skill, though care needs to be taken that the trainee mediator does not become complacent, over-reliant on simplistic either/or approaches or unable to think in the moment.

Examples of stock reframes:

\begin{tabular}{|l|l|}
\hline Reframe from & To \\
\hline She doesn't listen. & You need to be heard? \\
\hline It's a complete failure. & What can be learned from this? \\
\hline It's a dangerous threat. & Is there also an opportunity here? \\
\hline It can't get any worse. & Can you conceive of how it can get better? \\
\hline Criticism & Feedback \\
\hline
\end{tabular}

Metaphors provide a way to enrich reframing interventions: sports (reaching your goal, that was off-side, have a time-out); construction (this will provide a good foundation, the agreement is still a bit shaky); travel (I think we're getting somewhat lost here, what road map will get you to your destination); and colours (this is very black and white). It is especially useful if the mediator notices a metaphor being used by a party and then speaks to them in the same metaphor - even if this is very obvious it can raise a chuckle, and appropriate good humour introduced in a mediation setting has a relaxing effect on parties. An example from team mediation: some of the parties have been speaking about how groups of staff meeting at coffee or lunch have undermined the manager's role and authority. They refer to these cliques as 'lunch clubs' and 'coffee cabinets'. The other parties describe how they have noticed that the managers meet together after work in the golf club and at dinner events and believe they are plotting against the staff. The mediation session breaks for lunch and at the re-start, the mediator asks "So, how did the lunch clubs go?" rather than simply "How was lunch?" This results in some smiles, shows the mediator is engaged and is aware of the issue, and uses the metaphorical language of the parties to plug into the meaning without having to provide copious explanation.

Referring back to the world of advertising, one interesting way for mediators to think about reframing is to use Carlberg's advertising line: "It's not just A or B, there's probably a C." The C, of course, referred to Carlsberg but we can use it thus: "It's not just A (i.e. party A's framing) or B (i.e. party B's framing), there's probably a C (i.e. the mediator's reframing)."

\section{Conclusion}

Parties will not always respond positively towards reframing attempts by the mediator. If used too early in the process resistance and suspicion may still be high and a party may see the mediator's efforts as manipulation or justifying the other party's position.

Reframes need to be communicated in a tentative manner and the mediator should always remain humble - what to the mediator appears to be a wonderful reframe may not appear so to the party.

Reframing is about change. Once someone's mind has opened to another viewpoint and meaning it is possible for them to consider a range of ideas and solutions that would otherwise have been 
inconceivable.

An apt quotation to frame the conclusion is from Max Planck, the renowned Nobel winning quantum physicist, who said: "When we change the way we look at things, the things we look at change."

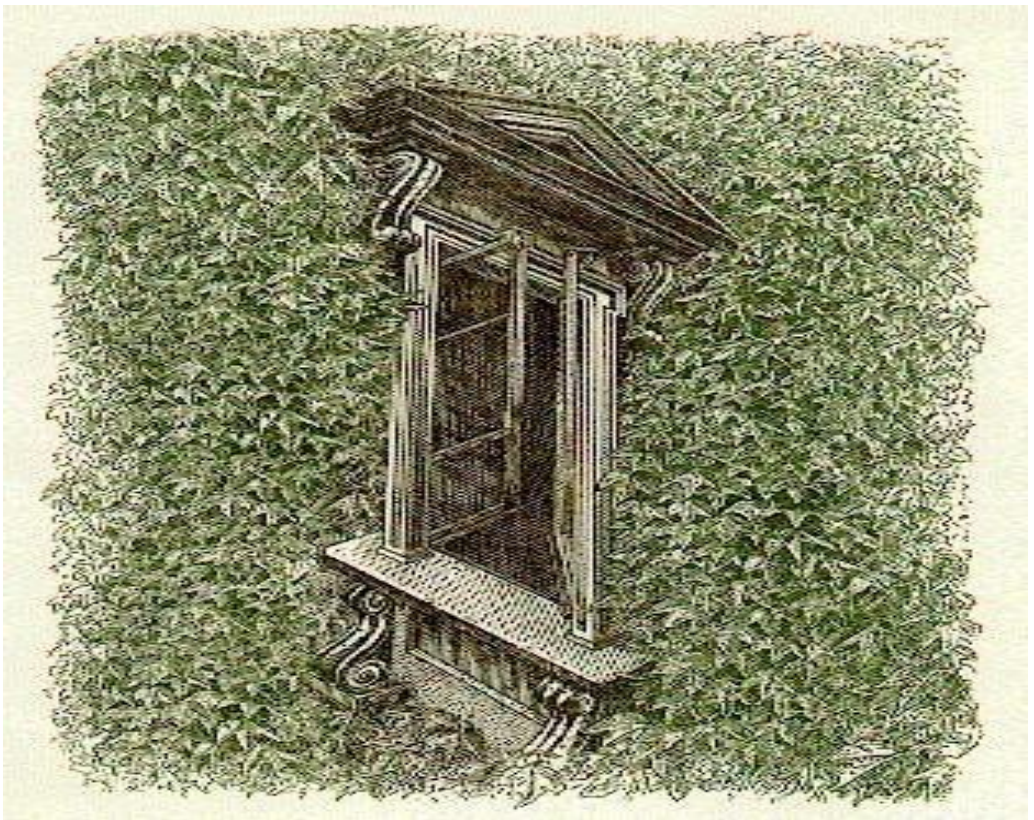

In this image the window can appear to open either outward or inward, depending on whether the viewer focuses on the top part of the window frame or the bottom. The image does not change, but the perception changes depending on the viewer's focus. Using words instead of an image, a mediator can create a reframe by drawing attention to an aspect of the conflict that the parties have not noticed or considered.

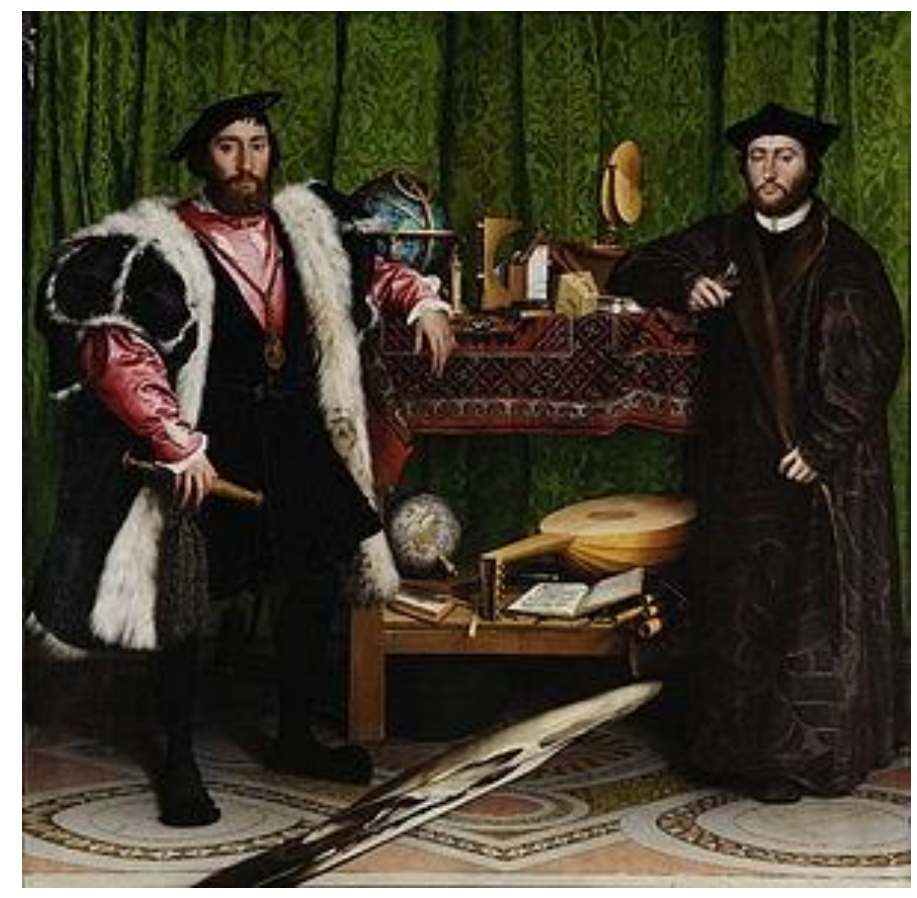


The image of the skull in Hans Holbein the Younger's 'The Ambassadors' (1533) is difficult to make out when viewed directly from the front. But by altering the perceptual position to view the painting from high on the right side or low on the left side, the correct form of the skull can be seen. In a similar way, a mediator can ask the parties to view the conflict from different perceptual positions of another person affected by the conflict. This perceptual shift can create a dissonance in the parties' view point which can then be used by the mediator to remind the parties of a 'bigger picture' of the conflict and provide richer raw material to work with.

Reframing is important for mediators because it is an active way of changing a party's inferred meaning which can result in renewed motivation and energy to work harder on reaching resolution. Where parties have become entrenched, defensive or feel hopeless, this burst of renewal can be like opening a door to let the light shine in. New insight from reframing allows parties to adjust and to think differently about the conflict and releases them to be creative in finding solutions. 


\section{References}

Bolman, L.G \& Deal, T.E 1997. Reframing Organizations: Artistry, Choice and Leadership

(Second Ed., San Francisco: Jossey-Bass, 1997), 280.

Mayer, B 2000. The Dynamics of Conflict Resolution (San Francisco: Jossey-Bass, 2000), 139. Shapiro, M. 1998. Neuro-linguistic Programming in a Week. (Hodder Arnold, 1998), 25.

The clip from the Ronald Reagan/Walter Mondale debate can be seen on https://www.youtube.com/watch?v=fjhCjMfRndk

'The Ambassadors' by Hans Holbein the Younger, 1533, National Gallery, London

Max Planck's quotation is from http://www.goodreads.com/author/quotes/107032.Max Planck

Kaufman, Sanda, M. Elliott and D. Shmueli.2003 "Frames, Framing and Reframing." Beyond Intractability.

Eds. Guy Burgess and Heidi Burgess. Conflict Information Consortium, University of Colorado, Boulder.

Posted: September 2003.

Brendan Schutte is one of the pioneers of workplace mediation in Ireland and the UK. Following a successful career in Human Resource Management and Development, Brendan became an independent consultant in 2000 offering mediation, investigation, independent review, training and advice. He has worked across a wide diversity of organisations and was the first Registrar for the Workplace Sector in the Mediators Institute of Ireland. Author of "Fixing the Fighting" (Oak Tree Press, 2003) and an audio CD entitled "Active Listening" (2014). For more information see www.brendanschutte.com. 